\title{
Comprimento da estaca no desenvolvimento de mudas de alecrim-pimenta
}

\author{
Effect of cutting length on the development of pepper-rosmarin seedlings
}

\author{
Wellington Geraldo Oliveira Carvalho Júnior ${ }^{\mathrm{I}}$ Marco Túlio Pinheiro de Melo II \\ Ernane Ronie Martins ${ }^{\text {III }}$
}

\begin{abstract}
O objetivo deste trabalho foi avaliar a influência do comprimento de estacas caulinares no desenvolvimento de mudas de alecrim-pimenta (Lippia sidoides Cham.). As estacas foram coletadas de plantas matrizes do Horto Medicinal do Instituto de Ciências Agrárias da Universidade Federal de Minas Gerais, em Montes Claros, Minas Gerais. O experimento foi conduzido em casa de vegetação com nebulização intermitente. Utilizou-se o delineamento inteiramente casualizado, com quatro tratamentos e cinco repetições. Os tratamentos foram definidos pelos intervalos de comprimento das estacas (5 a $8 \mathrm{~cm}, 8,1 \mathrm{a} 11 \mathrm{~cm}, 11,1 \mathrm{a} 14 \mathrm{~cm}$ e $14,1 \mathrm{a} 17 \mathrm{~cm})$. Foram avaliados o número de raízes principais, o comprimento da maior raiz (cm), o número de brotações, a porcentagem de enraizamento, a avaliação visual do enraizamento e a fitomassa seca das brotações e das raízes $(\mathrm{g})$. Os resultados indicam que o comprimento das estacas afeta o desenvolvimento de mudas de alecrim-pimenta, especialmente a fitomassa seca das brotações e das raízes. As estacas com 14,1 a $17 \mathrm{~cm}$ apresentaram a maior porcentagem de enraizamento $e$ as maiores médias para as outras variáveis analisadas, sendo, portanto, mais recomendadas para a propagação vegetativa de alecrim-pimenta.
\end{abstract}

Palavras-chave: Lippia sidoides Cham., plantas medicinais, propagação vegetativa, estaquia.

\section{ABSTRACT}

This research aimed to evaluate the effect of shoot cutting length on the development of pepper-rosmarin seedlings (Lippia sidoides Cham.). The cuttings were obtained from stock plants of the medicinal vegetable garden of Instituto de Ciências Agrárias/UFMG, Montes Claros, Minas Gerais, Brazil. The experiment was conducted in greenhouse conditions with intermittent mist. The experimental design was totally randomized with four treatments consisted of different size intervals (5 to $8 \mathrm{~cm}, 8.1$ to $11 \mathrm{~cm}, 11.1$ to $14 \mathrm{~cm}$ and 14.1 to $17 \mathrm{~cm})$, with five replications each. The amount of shooting and root, the shooting and root dry weight $(\mathrm{g})$, the the longest root length $(\mathrm{cm})$, the visual rooting evaluation and the rooting percentage were analysed. The results indicated that cutting length affects the development of pepper-rosmarin seedlings, especially shooting and root dry weight. The cuttings with 14.1 until $17 \mathrm{~cm}$ presented the highest percentage of rooting and the largest average of the other variables, being the most recommended to be used in the propagation of pepperrosmarin.

Key words: Lippia sidoides Cham., medicinal plants, vegetative propagation, cutting.

A espécie Lippia sidoides Cham. (Verbenaceae) é nativa da vegetação do semiárido brasileiro, conhecida como alecrim-pimenta e, geralmente, utilizada pela população local na preparação de medicamentos antissépticos (MATOS \& OLIVEIRA, 1998; MATOS et al., 1999). Trata-se de um arbusto densamente ramificado de até três metros de altura com ramos providos de folhas muito aromáticas e picantes (LORENZI \& MATOS, 2002).

ICurso de Engenharia Agronômica, Instituto de Ciências Agrárias (ICA), Universidade Federal de Minas Gerais (UFMG), 39400000, Montes Claros, MG, Brasil. E-mail: carvalhojunior17@yahoo.com.br. Autor para correspondência.

${ }^{\mathrm{II}}$ Curso de Engenharia Agronômica, ICA/UFMG, Montes Claros, MG, Brasil.

IIILaboratório de Plantas Medicinais e Aromáticas, ICA/UFMG, Montes Claros, MG, Brasil. 
LEMOS et al. (1990) demonstraram, por meio da análise da composição química do óleo essencial, que o timol e o carvacrol são os componentes majoritários deste, sendo atribuída a esses monoterpenos a atividade antimicrobiana exibida pela espécie.

O alecrim-pimenta é dificilmente propagado via semeadura, dada à dificuldade de coleta e manipulação das sementes, que são muito pequenas e ainda possuem baixos índices de germinação (MATOS \& OLIVEIRA, 1998). Os mesmos autores recomendam, portanto, a estaquia na multiplicação da espécie. OLIVEIRA et al. (2008a), testando diferentes tipos de estacas na propagação do alecrim-pimenta, concluíram que as estacas apicais apresentaram maior número de raízes em comparação com aquelas retiradas da porção mediana do ramo, indicando, portanto, as estacas apicais como mais apropriadas ao processo.

Estudos sobre a propagação de espécies medicinais são de elevada importância, uma vez que servem de base para a domesticação e o sucesso do cultivo dessas plantas. No entanto, ainda há escassez desses estudos, como no caso do alecrim-pimenta, especialmente quando ainda não há informações precisas quanto ao tamanho de estaca a ser utilizada. Esse fator parece ser de grande relevância para que o processo da estaquia seja bem sucedido, de forma que os trabalhos com as espécies Ocimum gratissimum (EHLERT et al., 2004), Ocimum selloi (COSTA et al., 2007), Hylocereus undatus (BASTOS et al., 2006), Cissus sicyoides (ABREU et al., 2003), Malpighia emarginata (LIMA et al., 2006) e Pfaffia glomerata (NICOLOSO et al., 2001) corroboram tal hipótese.

Objetivando-se contribuir para a melhoria do processo de produção de mudas de alecrim-pimenta, este trabalho visa a avaliar a influência de diferentes comprimentos de estacas caulinares no desenvolvimento de mudas da espécie. Para tanto, o trabalho foi conduzido em condições de casa de vegetação com nebulização intermitente, no período de janeiro a março de 2008. Foram coletadas estacas apicais herbáceas de plantas matrizes de $\boldsymbol{L}$. sidoides do Horto Medicinal do Instituto de Ciências Agrárias da Universidade Federal de Minas Gerais, localizado na cidade de Montes Claros, em Minas Gerais (MG). Em seguida, as estacas foram classificadas nos tratamentos, sendo estes definidos pelos intervalos de comprimento: T1 - 5 a 8cm; T2 - 8,1 a 11cm; T3 11,1 a 14cm; e T4 - 14,1 a 17cm. As folhas medianas e basais foram removidas, deixando-se um par de folhas apicais, com apenas a metade de sua área foliar.

O delineamento experimental utilizado foi o inteiramente casualizado, com quatro tratamentos e cinco repetições, sendo 10 estacas por parcela.
Utilizaram-se bandejas plásticas preenchidas com o substrato comercial Plantmax ${ }^{\circledR}$. Após 40 dias do plantio das estacas, foram avaliados o número de raízes principais, o comprimento da maior raiz (em centímetros), o número de brotações, a porcentagem de enraizamento, a avaliação visual do enraizamento e a fitomassa seca das brotações e das raízes (em gramas). Utilizaram-se paquímetro digital com precisão de centésimo de milímetro para a medição das raízes e balança digital analítica com precisão de milésimo de grama para a determinação das fitomassas. Na avaliação visual do enraizamento de cada estaca, foram atribuídas notas de 0 (níveis de enraizamento inferiores) a 5 (níveis de enraizamento superiores), por dois avaliadores, sendo considerada a média aritmética dessas notas como nota final da avaliação. Os dados foram submetidos à análise de variância pelo teste F. Em seguida, as médias foram comparadas pelo teste Scott \& Knott, em nível de 5\% de probabilidade de erro, para ambos os testes. Para a análise estatística, utilizou-se o programa SAEG - Sistema para Análises Estatísticas e Genéticas (RIBEIRO JÚNIOR, 2001). Os dados de número de raízes principais, de número de brotações e da avaliação visual do enraizamento foram transformados em $\sqrt{X+0,5}$, e a porcentagem de enraizamento foi transformada em arco-seno $\sqrt{X / 100}$, uma vez que tais dados não apresentaram variâncias homogêneas pelo teste de Hartley. Para os dados referentes à contagem e atribuição de notas, por seguirem a distribuição de Poisson, utilizou-se a transformação de raiz quadrada, já para aqueles dados referentes às porcentagens, por seguirem a distribuição binomial, procedeu-se à transformação angular (BANZATTO \& KRONKA, 2006).

Nota-se que as estacas de maior comprimento apresentaram os melhores resultados para as variáveis analisadas (Tabela 1). As estacas com tamanho entre 5 e $11 \mathrm{~cm}$ apresentaram porcentagens de enraizamento inferiores, diferindo significativamente dos demais tratamentos pelo teste de Scott \& Knott, em nível de $5 \%$ de probabilidade de erro. Esse fato pode ser explicado pelo baixo nível de reservas energéticas presentes nessas estacas, como sugerido por NICOLOSO et al. (2001). OLIVEIRA et al. (2008a), estudando a propagação por estaquia do alecrimpimenta, obtiveram médias de porcentagem de enraizamento bastante inferiores às apresentadas neste trabalho. A maior média obtida por esses autores foi de $60,86 \%$, enquanto que a menor média relativa à porcentagem de enraizamento obtida no presente trabalho foi de $84 \%$. Tais resultados contrastam-se, possivelmente, pela ausência de nebulização intermitente naquele estudo, condição que, segundo 
Tabela 1 - Efeito do comprimento da estaca apical herbácea de alecrim-pimenta (Lippia sidoides Cham.) nas médias de número de raízes principais (Nraiz), número de brotações (Nbrot), comprimento da maior raiz (Cmaior), fitomassa seca das brotações (FSBr), fitomassa seca das raízes (FSR), avaliação visual do enraizamento (Nota) e porcentagem de enraizamento (Enrt). ICA/UFMG, Montes Claros-MG, 2008.

\begin{tabular}{|c|c|c|c|c|c|c|c|}
\hline Comprimento da estaca (cm) & Nraiz $^{\text {ns }}$ & Nbrot* & Cmaior $(\mathrm{cm})^{\mathrm{ns}}$ & $\mathrm{FSBr}(\mathrm{g})^{*}$ & $\operatorname{FSR}(\mathrm{g})^{*}$ & Nota* & Enrt $(\%)^{*}$ \\
\hline 5 a 8 & 13,50 & $2,05 \mathrm{~b}$ & 99,31 & $0,25 \mathrm{c}$ & $0,18 \mathrm{c}$ & $3,03 \mathrm{~b}$ & $84 \mathrm{~b}$ \\
\hline 8,1 a 11 & 13,46 & $2,10 \mathrm{~b}$ & 87,21 & 0,48 c & $0,23 \mathrm{c}$ & $2,98 \mathrm{~b}$ & $88 \mathrm{~b}$ \\
\hline 11,1 a 14 & 14,44 & $2,65 \mathrm{a}$ & 92,91 & $0,78 \mathrm{~b}$ & $0,37 \mathrm{~b}$ & $3,41 \mathrm{a}$ & $96 \mathrm{a}$ \\
\hline 14,1 a 17 & 17,76 & $2,84 \mathrm{a}$ & 104,93 & 1,10 a & $0,59 \mathrm{a}$ & 3,85 a & 98 a \\
\hline Média & 14,79 & 2,41 & 96,09 & 0,65 & 0,34 & 3,3 & 91,5 \\
\hline CV (\%) & 13,43 & 5,63 & 14,92 & 34,86 & 28,79 & 5,00 & 13,60 \\
\hline
\end{tabular}

* Médias seguidas pela mesma letra, nas colunas, não diferem estatisticamente entre si pelo teste Scott \& Knott, em nível de 5\% de probabilidade de erro.

${ }^{\mathrm{ns}}$ Não houve efeito significativo entre os tratamentos.

HARTMANN et al. (2002), controla a perda de água pelas estacas e reduz as temperaturas da folha e do ar circunvizinho, sendo fatores que poderiam auxiliar o processo de enraizamento.

Observa-se que a avaliação visual do enraizamento apresentou resultados estatísticos similares às variáveis número de brotação e porcentagem de enraizamento, indicando que a atribuição de notas por avaliadores é uma medida eficiente na identificação de materiais propagativos com alta propensão ao bom desenvolvimento de novas plantas de alecrim-pimenta.

O tamanho das estacas não influenciou significativamente o número de raízes principais e o comprimento da maior raiz, resultado semelhante aos resultados encontrados por ABREU et al. (2003), ao trabalharem com Cissus sicyoides, e por OLIVEIRA et al. (2008b), ao trabalharem com Melaleuca arternifolia, os quais relacionaram esse evento ao número de folhas mantidas nas estacas, que é proporcional à quantidade de fotoassimilados fornecidos para a formação das raízes.

Observou-se expressiva influência do tamanho das estacas nas fitomassas secas das brotações e das raízes, e as estacas maiores que $14 \mathrm{~cm}$ (tratamento 4) apresentaram os melhores resultados (Tabela 1). Esse fato comprova que houve maior emissão de brotações neste tratamento e que o sistema radicular dessas estacas apresentava-se bastante ramificado, mais uma vez indicando maior vigor do material propagativo formado, como consequência do maior teor de reservas de carboidratos que as estacas maiores certamente apresentam (HARTMANN et al., 2002; NICOLOSO et al., 2001). A maior ramificação das raízes implica um aumento da área de solo a ser explorada, aumentando-se a taxa de absorção de água e nutrientes, o que certamente proporcionaria um melhor desenvolvimento da muda quando levada a campo. Do mesmo modo, há um incremento na qualidade da muda formada em decorrência da maior quantidade de brotações emitidas, pois amplia-se a capacidade fotossintética e, consequentemente, o potencial de estabelecimento em campo.

Conclui-se que o tamanho das estacas de alecrim-pimenta afeta o desenvolvimento de mudas dessa espécie quando em condições de casa de vegetação com nebulização intermitente. São recomendadas as estacas apicais herbáceas de tamanho compreendido entre 14,1 e $17 \mathrm{~cm}$ de comprimento.

\section{AGRADECIMENTOS}

Ao Programa de Educação Tutorial (PET/SesuMEC), pela concessão de bolsa a W. G. O. Carvalho Júnior, e ao Conselho Nacional de Desenvolvimento Científico e Tecnológico (CNPq), pela concessão de bolsa de Iniciação Científica a M. T. P. de Melo. Ao Fundo de Desenvolvimento Científico e Tecnológico do Banco do Nordeste do Brasil (BNBFUNDECI), pelo auxílio financeiro.

\section{REFERÊNCIAS}

ABREU, I.N. et al. Propagação in vivo e in vitro de Cissus sicyoides, uma planta medicinal. Acta Amazônica, Manaus, v.33, n.1, p.1-7, 2003.

BANZATTO, D.A.; KRONKA, S.N. Experimentação agrícola. Jaboticabal: FUNEP, 2006. 237p.

BASTOS, D.C. et al. Propagação da pitaya 'vermelha' por estaquia. Ciência e Agrotecnologia, Lavras, v.30, n.6, p.1106-1109, 2006. Disponível em: <http://www.scielo.br/ scielo.php ? script = sci_art text \& pid = S 1413 70542006000600009\&lng=en\&nrm=iso>. Acesso em: 13 Jan. 2009. doi: 10.1590/S1413-70542006000600009. 
COSTA, L.C. et al. Comprimento da estaca e tipo de substrato na propagação vegetativa de atroveran. Ciência Rural, Santa Maria, v.37, n.4, p.1157-1160, 2007. Disponível em: <http:/ /www.scielo.br/scielo.php?script=sci_arttext\&pid=S010384782007000400040\&lng=en\&nrm=iso>. Acesso em: 17 Jun. 2008. doi: 10.1590/S0103-84782007000400040.

EHLERT, P.A.D. et al. Propagação vegetativa da alfavaca-cravo utilizando diferentes tipos de estacas e substratos. Horticultura Brasileira, Brasília, v.22, n.1, p.10-13, 2004. Disponível em: $<$ http://www.scielo.br/scielo.php?script=sci_arttext\&pid=S0102$05362004000100002 \& \operatorname{lng}=$ en $\& n r m=i s o>$. Acesso em: 13 Jan. 2009. doi: 10.1590/S0102-05362004000100002.

HARTMANN, H.T. et al. Plant propagation: principles and practices. New Jersey: Prentice Hall, 2002. 880p.

LEMOS, T.L.G. et al. Antimicrobial activity of essential oil of Brazilian plants. Phytotherapy Research, New Jersey, v.4, n.2, p.82-84, 1990.

LIMA, R.L.S. et al. Comprimento de estacas e parte do ramo na formação de mudas de aceroleira. Revista Brasileira de Fruticultura, Cruz das Almas, v.28, n.1, p.83-86, 2006.

LORENZI, H.; MATOS F.J.A. Plantas medicinais no Brasil: nativas e exóticas. Nova Odessa: Instituto Plantarum, 2002. 512p.
MATOS, F.J.A. et al. Medicinal plants Northeast Brazil containing Thymol and Carvacrol- Lippia sidoides Cham. and Lippia gracillis H. B. K (Verbenaceae). Journal of Essential Oil Research, Wheaton, v.11, p.666-668, 1999.

MATOS, F.J.A.; OLIVEIRA, F. Lippia sidoides Cham. Farmacognosia, química e farmacologia. Revista Brasileira de Farmacognosia, João Pessoa, v.79, p.84-87, 1998.

NICOLOSO, F.T. et al. Comprimento da estaca de ramo no enraizamento de ginseng brasileiro (Pfaffia glomerata). Ciência Rural, Santa Maria, v.31, n.1, p.57-60, 2001. Disponível em: <http://www.scielo.br/scielo.php?script=sci_arttext\&pid=S010384782001000100009\&lng=en\&nrm=iso>. Acesso em: 8 Mai. 2008. doi: 10.1590/S0103-84782001000100009.

OLIVEIRA, G.L. et al. Enraizamento de estacas de Lippia sidoides Cham. utilizando diferentes tipos de estacas, substratos e concentrações do ácido indolbutírico. Revista Brasileira de Plantas Medicinais, Botucatu, v.10, n.4, p.12-17, 2008a.

OLIVEIRA, Y. et al. Comprimento das estacas no enraizamento de melaleuca. Scientia Agraria, Curitiba, v.9, n.3, p.415418, 2008b.

RIBEIRO JÚNIOR, J.I. Análises estatísticas no SAEG. Viçosa: UFV, 2001. 301p. 